\title{
LA LOGÍSTICA EN LA EXPULSIÓN DE LOS JESUITAS DE FILIPINAS: EL PAPEL DE LA MARINA
}

\author{
Santiago LORENZO GARCÍA \\ Universidad de Alicante
}

\begin{abstract}
Resumen
Este artículo pretende analizar la operación de extrañamiento planeada y ejecutada por el gobierno de Filipinas, la provincia hispana más alejada de la metrópoli. Deportar a casi centenar y medio de jesuitas rumbo a Europa acarreó no pocos inconvenientes a las autoridades políticas isleñas, especialmente a la hora de preparar los buques encargados de tan delicada misión. Factores como la insularidad y la lejanía hicieron de la Marina la pieza clave dentro del engranaje del extrañamiento filipino.
\end{abstract}

\begin{abstract}
This article tries to analyse the expulsion operation planned and executed by the government of Philippines, the remotest spanish province from the metropolis. To deport nearly one hundred an a half Jesuits towards Europe caused a lot of obstacles to the island political authorities, especially in order to prepare the vessels which were in charge of such a delicate mission. Thanks to factors as the insularity and the distance, the Navy was the key piece in the gear of the Philippines' expulsion.
\end{abstract}

La expulsión de más de 5.000 jesuitas de España en pleno siglo XVIII supuso un desafío a la técnología del momento y a la capacidad organizativa del gobierno de Carlos III. Fue preciso diseñar y llevar a la práctica una complicada maquinaria logística no vista hasta la fecha. Especialmente difícil fue coordinar todas las maniobras en los territorios de ultramar, allí donde las enormes distancias representaban el principal obstáculo para las instrucciones ordenadas desde Madrid. Finalizando el setecientos, la cohesión territorial de la Corona era una constante preocupación para el ejecutivo español, obsesionado por controlar desde el centro todo lo que sucedía en cualquier esquina de la Monarquía. Esta preocupación asomó ásperamente con ocasión de los acontecimientos de 1767.

Este artículo pretende analizar la operación de extrañamiento planeada y ejecutada por el gobierno de Filipinas, la provincia hispana más alejada de la metrópoli. 
Deportar a casi centenar y medio de jesuitas rumbo a Europa acarreó no pocos inconvenientes a las autoridades políticas isleñas, especialmente a la hora de preparar los buques encargados de tan delicada misión. Como veremos, la insularidad y la lejanía hicieron de la Marina la pieza clave dentro del engranaje del extrañamiento filipino.

\section{LA MARINA Y EL EJÉRCITO: INSTRUMENTOS PARA LA EXPATRIACIÓN}

El 27 de febrero de 1767 el Rey firmó el famoso Decreto ordenando «extrañar de todos mis dominios de España, Indias, islas Filipinas y demás adyacentes a los regulares de la Compañia»'. El documento tenía como destinatario último al Conde de Aranda, capitán general y presidente del Consejo de Castilla y del Extraordinario. Fue Aranda el encargado de tomar el relevo de Campomanes y Roda, autores de la parte ideológica de la «operación cesárea», pasando a la acción y diseñando el plan práctico de expulsión ${ }^{2}$. Sus líneas maestras apuntaron hacia la rapidez y la discreción, y Aranda vio en el Ejército y la Marina los instrumentos idóneos para llevar a buen puerto un proyecto de esta envergadura.

Efectivamente, las tropas terrestres tuvieron la iniciativa en la primera etapa del guión de Aranda. Así lo dispuso en la Instrucción de 1 de marzo de 1767, que envió a los comisionados. Siguiendo las indicaciones del documento, la víspera de la fecha señalada cada uno de ellos «disimuladamente echará mano de la tropa presente o inmediata, o en su defecto se reforzará de otros auxilios de su satisfacción, procediendo con presencia de ánimo, frescura y precaución, tomando desde antes del día las avenidas del colegio o colegios» ${ }^{3}$. Al mismo tiempo, los soldados recibirían órdenes de vigilar las calles y plazas próximas a las residencias. Más tarde, al amanecer, los delegados reales entrarían en las casas, acompañados de una pequeña fuerza armada. Tras intimarles el Real Decreto, los padres debían ser trasladados, en un plazo no mayor a veinticuatro horas, a un lugar de reunión designado previamente, «depósitos interinos o cajas que irán señaladas»; la «conducción se pondrá al cargo de personas prudentes y escolta de tropa o paisanos ${ }^{4}$. A las puertas del colegio una guardia reducida se haría cargo de la seguridad del recinto, impidiendo la entrada en el mismo. «Desde dichos depósitos, que no sean marítimos, se sigue la remisión a su embarco».

Una vez llegados los religiosos a los puertos de embarque, la Marina tomaba el protagonismo dentro del dispositivo diseñado. La Secretaría de Marina e Indias, al

1. A.G.S., Gracia y Justicia, leg. 690: Real Decreto de expulsión de la Compañía de Jesús, Madrid, 27 de febrero de 1767.

2. Sobre el papel del Conde de Aranda en la mecánica de expulsión ver LORENZO GARCÍA, Santiago, «El Conde de Aranda y la expulsión de los jesuitas de Filipinas», en Actas del Congreso Internacional El Conde de Aranda y su tiempo (Zaragoza, 1-5 de diciembre de 1998), Institución «Fernando el Católico», en prensa.

3. A.G.S., Gracia y Justicia, leg. 690: «Instrucción de lo que deberán ejecutar los Comisionados para el extrañamiento y ocupación de bienes y haciendas de los jesuitas en estos Reinos de España e Islas adyacentes, en conformidad de lo resuelto por S. M.», Madrid, 1 de marzo de 1767.

4. Ibidem.

5. Ibídem. 
frente de la cual se encontraba por entonces Julián de Arriaga, tuvo como misiones pertrechar los buques de guerra y mercantes necesarios para el transporte a Italia, y atender a las cuestiones del rancho y víveres para el viaje ${ }^{6}$. En los muelles la supervisión de estas cuestiones recayó en los Intendentes de Marina, mientras que en alta mar los responsables de los regulares fueron comisarios designados por el Intendente, asumiendo el mando de cada convoy un comandante de fragata, encargado de llevar a su destino final a los barcos y pasajeros?

De este modo se organizaron cuatro expediciones desde la Península con destino al exilio italiano: los padres de la provincia de Castilla partieron de La Coruña y El Ferrol, bajo el mando de Diego de Argote; los de la provincia andaluza lo hicieron desde los puertos de Santa María y Málaga a las órdenes de Juan Manuel Lombardón; los regulares de la provincia de Toledo salieron de Cartagena con Francisco de Vera; y el célebre marino Antonio Barceló escoltó a los integrantes de la provincia de Aragón, que se hicieron a la vela en Salou, recogiendo a su paso por Palma de Mallorca a sus compañeros baleares ${ }^{8}$.

Salvo el contratiempo de Córcega, la expatriación de los padres peninsulares significó un sonado triunfo del regalismo hispano. No obstante, dentro de la mecánica global del extrañamiento, el Conde de Aranda sabía que, en el caso de las provincias ultramarinas, había que contar con una dificultad añadida a todas las demás: la lejanía. Las enormes distancias hacían imposible un control directo sobre todos los territorios de la Monarquía, incluso en asuntos de tanta trascendencia. Donde no alcanzaba el brazo regalista de Carlos III y sus ministros, debían ser sus máximos representantes los que organizasen el obligado exilio jesuítico:

"Para que los virreyes, presidentes y gobernadores de los dominios de Indias e Islas Filipinas se consideren con las mismas facultades conducentes, que en mi residen en virtud de la Real Resolución, depongo en ellos las de que habla la instrucción de España, para dar las órdenes, señalando las cajas de depósito y embarcaderos, como aprontando las embarcaciones necesarias para transporte de los jesuitas a Europa y Puerto de Santa María, donde se recibirán y aviarán para su destino»."

6. GIMÉNEZ LÓPEZ, Enrique, «El Ejército y la Marina en la expulsión de los jesuitas de España», Hispania Sacra, vol. XLV (1993), núm. 92, p. 582.

En este estudio el profesor Giménez realiza un análisis profundo de las claves que marcaron la expulsión de los jesuitas de las cuatro provincias peninsulares (Castilla, Aragón, Toledo y Andalucía), atendiendo especialmente al papel jugado por el Ejército y la Marina en la operación. Su lectura nos ha servido como valiosa fuente de información y de inspiración en algunas partes de nuestro trabajo sobre Filipinas.

7. Ibidem, pp. 582-591.

8. Ibidem, pp. 581-582 y $590-591$.

9. A.G.S., Gracia y Justicia, leg., 690: Adición a la Instrucción sobre el extrañamiento de los jesuitas de los dominios de S. M. por lo tocante a Indias e Islas Filipinas. 


\section{EL GOBERNADOR RAÓN; PRIMEROS PASOS EN LA EXPULSIÓN DE LOS JESUITAS DE FILIPINAS}

En Filipinas fue el gobernador y capitán general José Raón quien tuvo que diseñar la estrategia de expulsión. Tras la sorpresa inicial que provocó en las Islas la Real Orden, Raón nombró el 18 de mayo de 1768 al oidor Manuel Galbán y Ventura juez comisionado para el extrañamiento de los jesuitas ${ }^{10}$. Sin perder tiempo, el 19 de mayo por la mañana el comisionado, en compañía de una reducida fuerza armada, se trasladó al Colegio de San Ildefonso, casa profesa, e intimó el Decreto a su comunidad. Paralelamente se dispuso que tropas de granaderos del regimiento de Santiago rodeasen las demás residencias jesuíticas de Manila y alrededores. En las jornadas sucesivas Galbán efectuó las mismas diligencias en cada una de ellas, mientras la Pragmática Sanción se hacía pública en las calles y plazas de la capital. La «caxa común de la provincia donde vinieron a parar todos los sujetos de ella» fue el Colegio de San Ignacio de Manila, donde, a mediados de junio, ya se encontraban recogidos todos los religiosos de la isla de Luzón ".

A primeros de julio comenzaron los preparativos para expulsar al primer contingente de regulares, compuesto por los padres que se encontraban confinados en el Colegio Máximo, en esas fechas. Primero se decidió que la travesía se realizase por la vía de Nueva España, aprovechando las favorables condiciones climáticas de esa época del año; el barco elegido a tal fin fue la fragata San Carlos Borromeo. Después, el gobierno de Manila proporcionó al capitán del buque, Felipe Cerain, 19.100 pesos para adquirir los abastos imprescindibles para el viaje. La comida representó la parte esencial del rancho: bizcocho, harina, azúcar, fideos de arroz, huevos, queso, jamón y embutido, carne y pescado fritos, cebollas, ajos, calabazas, repollo, tomates fritos, col en salmuera, aceitunas, chocolate, dulces de frutas, caramelo, mantequilla, aceite, especias y condimentos (pimienta, mostaza y comino), ganado y bestias vivas (cerdos, lechones, cabras, gansos y gallinas)... Además del agua, otras bebidas embarcadas fueron vino de coco, vino de Jerez, vinagre, zumo de limón, aguardiente y café. Las provisiones se completaron con ropa (chupas, camisas y gorros de lienzo, calzones, mantas y sábanas, paños de manos, medias, zapatos, escarpines, etc.), medicinas, útil de vajilla e instrumentos de cocina ${ }^{12}$.

10. SCHÜTTE, Josef Franz, El «Archivo del Japón». Visicitudes del Archivo Jesuitico del Extremo Oriente y Descripción del fondo existente en la Real Academia de la Historia de Madrid, Archivo Documental Español, Real Academia de la Historia, tomo XX, Madrid, 1964, p. 58.

11. «Arresto y viaje de los jesuitas de Filipinas, escrito por el Padre Francisco Javier Puig, individuo de dicha Provincia», pp. 58-60. En CUSHNER, Nicholas P., Philippine Jesuits in Exile, Roma, 1964.

12. A.H.N., Clero, Jesuitas, leg. 240: «Testimonio del expediente seguido por Don Felipe de Cerain, comandante de la fragata de S. M. nombrada San Carlos, que viajaba al Puerto de Acapulco el año de 68 y por un temporal furioso que le sobrevino volvió de arribada en el mismo año. Sobre que se le reciba el sobrante de rancho que preparó para la alimentación de los 64 regulares de la Compañia y otros que se refieren que iban embarcados en ella y se obligó a alimentarlos hasta dicho puerto por las cantidades que constan en la obligación que otorgó». 
Aparte del tipo de alimentos escogidos, poco sabemos del menú diario que se elaboró para un viaje de esas proporciones. El profesor Enrique Giménez ha estudiado este aspecto en cuanto a los jesuitas de Castilla, Aragón, Toledo y Andalucía, que fueron embarcados rumbo a tierras italianas. En este caso, las autoridades regularon al detalle todo lo referente a la alimentación a bordo. El desayuno estaba compuesto por chocolate, bizcochos y pan tostado. En las comidas se diferenciaba entre las jornadas de carne y las de vigilia. Dependiendo de esta distinción, el primer plato podía ser de sopa, arroz, fideos, sémola o garbanzos, acompañado o no de embutidos, mientras que el segundo podía incluir carne o pescado asados o en guiso, o bien huevos en tortilla, estrellados o cocidos. En la cena se turnaban las ensaladas, la carne y el atún guisados y los huevos ${ }^{13}$. Por la similitud de los ingredientes utilizados en ambos casos, podemos suponer que la dieta de los jesuitas filipinos fue, durante su peregrinaje marino, muy parecida a la de sus compañeros peninsulares; sin embargo, la entidad transoceánica del viaje de los primeros hizo que tuviesen que recurrir a alimentos conservados en salazón, manteca y especias, como parte básica de su nutrición.

El 3 de agosto el San Carlos zarpó del Puerto de Cavite rumbo a Acapulco, con 64 religiosos y 11 sirvientes a bordo. El viaje resultó catastrófico. Un terrible baguío azotó el navío entre el 8 y el 11 de septiembre ${ }^{14}$. La fragata quedó maltrecha, inútil para proseguir su camino. La tripulación se reunió apresuradamente en junta el día 12 para evaluar los daños y decidir sobre si seguir hacia Acapulco o regresar a Filipinas, optándose por lo segundo ${ }^{15}$. Cuando faltaba poco para retornar al Puerto de Cavite, otra tormenta de menor intensidad cayó sobre la nave entre el 29 de septiembre y el 1 de octubre. El Padre Provincial Juan Silverio Prieto y el P. Baltasar Vela, de 64 años, murieron como consecuencia de las tempestades ${ }^{16}$. Al amanecer del 9 de octubre se avistó la costa de la isla de Samar y, finalmente, el día 22 el San Carlos ancló en Ca-

13. GIMÉNEZ LÓPEZ, E. op. cit., p. 603.

14. Diario del P. Francisco Javier Puig, op. cit., pp. 70-72.

15. A.H.N., Clero, Jesuitas, leg. 238: «Testimonio literal de la Representación de Don Felipe de Cercin, general de la fragata San Carlos, en que da cuenta de su arribada», Manila, 25 de octubre de 1768.

Los daños sufridos por el San Carlos fueron realmente graves, según se desprende del testimonio del Piloto Mayor Santiago Salaberria: «... el estado tan deplorable en que ha quedado el barco con el furioso tiempo que hemos experimentado, con cincuenta y cuatro puntos de agua en la bodega, las bonbas casi inservibles, desarbolados los palos mayor y mesana, sin verga de trinquete velacho, $n i$ cebadera...».

EI San Carlos era un barco del tipo fragata, embarcación de guerra de menor tamaño que el navío, pero con similar aparejo de tres palos cruzados. El palo mayor es el central, el más alto y el que sustenta la vela principal; el mástil mesana es el que se sitúa a popa; el trinquete velacho equivale a la vela mayor del mástil de proa; y la vela cebadera es la que se tiende en cruz bajo el bauprés (palo grueso colocado en la proa), fuera de la embarcación. La fragata surcó los mares durante los siglos XVII y XVIII.

En MANERA REGUEYRA, E. y otros, El buque en la Armada española, Sílex, Madrid, 1981, p. 396.

16. A.H.N., Clero, Jesuitas, leg. 240: Carta de Felipe Cerain, capitán del San Carlos, a José Raón, 16 de octubre de 1768. 
vite, trasladándose de nuevo a los regulares al Colegio de San Ignacio ${ }^{17}$. Este contratiempo creó malestar en Madrid y un creciente nerviosismo en Manila, que se tradujo incluso en la apertura de una pesquisa para dilucidar si en el comportamiento de Cerain durante la travesía hubo algún tipo de negligencia ${ }^{18}$.

Otras circunstancias que obligaban forzosamente a demorar el destierro se añadieron a los recelos de Madrid y a las preocupaciones de Manila. No existía en ese momento en el archipiélago buque alguno preparado para realizar el viaje hacia Europa por el Cabo de Buena Esperanza y, por otro lado, el régimen de vientos sólo era favorable a la navegación desde las Filipinas hacia Nueva España en los meses de julio y agosto, por lo que los barcos que habían de transportar a los padres por esta vía no podrían partir hasta el verano del año siguiente ${ }^{19}$.

\section{EL TRANSPORTE INTERINSULAR: LOS PADRES DE BISAYAS Y MARIANAS A LA «CAJA GENERAL DE DEPÓSITO» EN MANILA}

La salida de los jesuitas confinados en Manila hacia Europa quedaba en suspenso. Pero, a finales del año 1768 , también quedaba pendiente la cuestión de los jesuitas de las islas Bisayas y de las misiones de Marianas. Por superior decreto de 14 de junio de ese año, Raón había ordenado a Fernando Caraveo Bolaño y Juan Francisco Romay, oficiales de la Real Hacienda, que pertrechasen varias embarcaciones para traer a los misioneros jesuitas de aquellas tierras a Manila, dejando en su sustitución a padres de otras religiones ${ }^{20}$.

Entre los barcos elegidos para tal fin se encontraban el balandro San Francisco de Asís, la goleta Nuestra Señora de Guadalupe, que fue reservada para Marianas, y el paquebote San Telmo ${ }^{21}$. Este último era propiedad de los dominicos de la provincia del Santo Rosario. Los oficiales de Real Hacienda mantuvieron negociaciones con su

17. A.H.N., Clero, Jesuitas, leg. 240: «Testimonio del expediente seguido por Don Felipe de Cerain, comandante de la fragata de S. M. nombrada San Carlos, que viajaba al Puerto de Acapulco el año de 68 y por un temporal furioso que le sobrevino volvió de arribada en el mismo año. Sobre que se le reciba el sobrante de rancho que preparó para la alimentación de los 64 regulares de la Compañia y otros que se refieren que iban embarcados en ella y se obligó a alimentarlos hasta dicho puerto por las cantidades que constan en la obligación que otorgón.

18. Cerain fue declarado inocente de esa acusación por sentencia de 31 de marzo de 1769 del oidor Henríquez de Villacorta, pero Ricardo de Villaseñor, defensor de los bienes ocupados a los regulares, le acusó asimismo de haber administrado arbitrariamente los 19.100 pesos que había recibido para cubrir los gastos del aprovisionamiento de los jesuitas. Por este motivo fue arrestado y estuvo a punto de ser relevado como comandante del San Carlos. Sin embargo, la premura por proseguir las operaciones de exirañamiento obligó a Raón a mantener a Cerain al mando de su fragata.

En A.H.N., Clero, Jesuitas, leg. 238: Fiscal Lorenzo de Andrade, Manila, 27 de octubre de 1768.

19. Diario del P. Francisco Javier Puig, op. cit., p. 84.

20. A.H.N., Clero, Jesuitas, leg. 245: Fernando Caraveo Bolaño y Juan Francisco Romay, en el Tribunal de Real Hacienda, Manila, 15 de julio de 1768.

21. El balandro es un pequeño buque de cubierta con un único mástil, vela cangreja (de figura trapezoidal) y foques (velas triangulares que se sitúan transversalmente entre los masteleros de proa y los botalones de bauprés). La goleta es un barco raso y fino de reducidas dimensiones, y de dos o tres palos no 
Procurador General fray José Azcárate, quien pidió por su compra 3.000 pesos. Se encargó entonces a Pascual de Torres y Baltasar de la Cruz, maestros de carpinteros del Real Arsenal del Puerto de Cavite, que examinasen la embarcación, tasando su valor total en 3.175 pesos. El 20 de julio la Junta de Real Hacienda, presidida por Raón, atendiendo a la rentabilidad de la operación, decidió su adquisición. Finalmente el 23 de agosto los dominicos percibieron de cuenta de la Caja de Temporalidades 2.901 pesos a cambio del paquebote ${ }^{22}$.

En el mes de septiembre de 1768 un pequeño convoy, encabezado por el San Telmo, partió rumbo a las Bisayas ${ }^{23}$. Como estaba previsto, formando parte de sus pasajes viajaban miembros de otras congregaciones religiosas, encargados de suceder a los hijos de San Ignacio en aquellas latitudes. Los agustinos y franciscanos se repartieron las misiones de las islas de Leyte y Samar; Panay y el oeste de la isla de Negros pasaron a manos de los dominicos; mientras que los agustinos recoletos reemplazaron al Instituto ignaciano en las peligrosas islas de Bohol y Mindanao ${ }^{24}$.

En el Colegio de San Ildefonso de Cebú (casa central de los jesuitas de Bisayas), las diligencias de intimación del Real Decreto fueron operadas el 17 de octubre de 1768 por José Andrés Velarde, Comandante general del Real Armamento de Pintados. Por entonces ocho eran los religiosos adscritos a dicho colegio, pero sólo cinco residían realmente en el centro, los otros realizaban su apostolado en los cercanos pueblos de Inabangan y Mandaui. Las actuaciones de Velarde, que comprendieron los preceptivos reconocimiento y tasación de los papeles y bienes ocupados, se alargaron hasta el verano de 1769. Por estas fechas los ocho jesuitas fueron embarcados rumbo a Manila, a bordo de la galera llamada del Santo Niño («Alias la Temible Cebuana»), al mando del capitán Juan Batistini ${ }^{25}$.

De modo que, a partir de finales de enero de 1769 y hasta el mes de julio, los regulares de las islas Bisayas fueron llegando a Manila en sucesivas tandas, engrosando el número de residentes en el Colegio Máximo de San Ignacio, «Caja General de Depósito» ${ }^{26}$.

cruzados -generalmente dos- con velas cangrejas. El paquebote es muy parecido al bergantín, aunque de líneas más gruesas, de dos palos (mayor y trinquete), con velas cuadradas y con gran cangreja como vela mayor.

En MANERA REGUEYRA, E. y otros, op. cit., pp. 381-413.

22. A.H.N., Clero, Jesuitas, leg. 245: «Testimonio del expediente formado a consulta de oficiales reales sobre la compra del paquebote nombrado San Telmo de la pertenencia de la Religión de la Provincia del Santo Rosario de estas Islas», Manila, junio-agosto de 1768.

23. Ibídem.

24. DE LA COSTA, Horacio, The Jesuits in the Philippines (1581-1768), Harvard University Press, Cambridge, 1961, pp. 591-592; y GUTIÉRREZ, Lucio, Historia de la Iglesia en Filipinas (1565-1900), Mapfre, Madrid, 1992, p. 56.

25. A.H.S.I.P.T., E-2: 94, 1-2 (leg. 535): «Extracto de los autos de ocupación del Colegio de Cebú», Manila, octubre de 1768 -junio de 1769.

26. En total llegaron a Manila 62 religiosos de las islas Bisayas repartidos en varios convoys.

A.H.N., Clero, Jesuitas, leg. 239: «Testimonio de las primeras diligencias de la comisión conferidas al Sr. Don Domingo Blas de Basaraz, oidor decano de esta Real Audiencia para que siga con la eje- 
Por razones lógicas de lejanía, la expedición de las islas Marianas fue más complicada y se retrasó más en el tiempo. El 21 de junio de 1769 José de Soroa, Intendente del Puerto de Cavite, había ofrecido sus servicios a las autoridades para hacerse cargo del transporte de los padres de Marianas, y siete días después el gobierno filipino dio el visto bueno a la propuesta. Soroa fue designado capitán del navío de Su Majestad Nuestra Señora de Guadalupe, con el que debía efectuarse la misión, disponiéndose igualmente que se preparase lo necesario para el viaje. El coste de la operación supuso para la Real Hacienda de Manila un desembolso de 4.742 pesos, 5 reales y 2 granos $^{27}$. Finalmente los tres padres de la Misión de las Marianas ingresaron en el Colegio Máximo de San Ignacio el día 28 de noviembre de $1769^{28}$.

\section{EL COMPLICADO VIAJE DEL SAN CARLOS POR LA VÍA DE NUEVA ESPAÑA}

Desde el inicio de 1769, el gobernador Raón y sus ministros, agobiados por la impaciencia reinante en Madrid, retomaron con energías renovadas las operaciones de expatriación de los jesuitas, con el claro objetivo de realizar «el mayor y último esfuerzo para que en este año salgan de Filipinas todos los regulares de la Compañía del nombre de Jesús» ${ }^{29}$. Atendiendo a esta propuesta, el gobernador decidió expatriar a los regulares por la vía de Nueva España, apta para la navegación entre los meses de julio y agosto; la ruta del Cabo de Buena Esperanza era más rápida, pero, si se escogía, la partida debía retrasarse hasta enero o febrero del año siguiente. De manera que se «mandó que por los señores oficiales reales se diesen las disposiciones conducentes, a fin de habilitar y expedir la fragata Santa Rosa para que el presente año hiciese viaje al Reino de Nueva España con el expresado destino, al mismo tiempo que la fragata San Carlos ${ }^{30}$. Se discutió, asimismo, sobre la posibilidad de contar en la operación con otro buque, el San José, que se estaba construyendo en esos momentos en los astilleros de la provincia de Pangasinan, aunque «no juzga Su Señoría que se puede contar con seguridad sobre este barco» ${ }^{31}$.

cución del Real Decreto de extrañamiento de los regulares de la Compañáa y ocupación de sus temporalidades por muerte del Señor D. Manuel Galbán y Ventura», Manila, 1 de junio de 1769.

27. Dentro del sistema monetario usado en Filipinas existían tres monedas: el peso, el real o tomín (que eran lo mismo) y el grano. Un peso equivalía a ocho reales o tomines. El real se subdividía a su vez en doce granos. Por lo tanto, en un peso había noventa y seis granos.

28. A.H.N., Clero, Jesuitas, leg. 242: «Testimonio literal del Expediente formado en virtud de Real Junta de Hacienda, en que se resolvió la habilitación de un barco para viajar a las islas Marianas, a fin de conducir los religiosos que deben remover a los de la Compañia que administran doctrina en ellas», Manila, junio de 1769.

29. A.H.N., Clero, Jesuitas, leg. 241: Junta General de Real Hacienda, Manila, 4 de febrero de 1769.

30. Ibídem.

31. Ibídem. 
De forma paralela se ordenó la preparación del rancho necesario para el viaje a Méjico. El comisionado encargado de esta tarea fue Fernando Caraveo Bolaño, Contador de la Real Hacienda. El 30 de enero el oficial envió una carta al P. José de León, con quien el gobierno filipino mantenía buenas relaciones, solicitándole la confección de una lista de todo lo necesario para el viaje de 130 religiosos hasta Acapulco. León respondió enviándole una amplia lista de abastos y su presupuesto, «diez a doce mil pesos poco más o menos». Las provisiones seleccionadas no eran diferentes a las del fallido periplo del San Carlos, sólo que, esta vez, en mayor cantidad ${ }^{32}$. La tripulación del buque debía estar formada, según el regular, por veinticuatro marinos «baqueanos en la carrera», «para que acomoden todo el rancho a bordo del navío y, como experimentados en dicho viaje, pongan a mano lo primero que se debe gastar como que va acomodado por ellos, sin que por esta ocupación dejen de servir sus plazas en que fueren empleados» ${ }^{33}$.

Se deseaba tener dispuesto ese rancho para mediados de mayo, optándose por comprar la vitualla en la isla de Java y en la rica Hacienda de Calamba, donde «ha de haber, si no el todo de este surtido, a lo menos mucha parte de él», sobre todo animales de ganado ${ }^{34}$.

Mientras estos preparativos eran ultimados contrarreloj, sucedió que el 31 de mayo de ese año murió el juez comisionado Manuel Galbán tras una penosa enfermedad ${ }^{35}$. Ese mismo día José Raón nombró como sustituto en el cargo al oidor Juan Domingo Blas de Basaraz, a quien se le notificó oficialmente la disposición el 1 de junio, comenzando inmediatamente su trabajo. El gobernador, políticamente mucho más en sintonía con Basaraz que con su antecesor en el puesto, le demandó que impusiese algo de orden en los asuntos de su nueva comisión, dejando caer implícitamente que Galbán no había operado en la misma con la diligencia necesaria ${ }^{36}$.

Al empezar el verano de 1769 se hizo evidente, contra las intenciones de las autoridades filipinas, que ese año era imposible expulsar a todos los religiosos por la ru-

32. A.H.N., Clero, Jesuitas, leg. 240: «Razón de los efectos que se consideran precisos para hacer el rancho de los ciento treinta PPs. de la Compañia, con sus respectivos criados, bodegueros y cocineros, que este presente año se han de embarcar para el Puerto de Acapulco por tiempo de siete meses».

33. Ibídem.

34. A.H.N., Clero, Jesuitas, leg. 240: Corespondencia entre Caraveo Bolaño y el P. José León, Manila, febrero y marzo de 1769.

35. A.H.N., Clero, Jesuitas, leg. 239: «Testimonio de las primeras diligencias de la comisión conferidas al Sr. Don Domingo Blas de Basaraz, oidor decano de esta Real Audiencia para que siga con la ejecución del Real Decreto de extrañamiento de los regulares de la Compañía y ocupación de sus temporalidades por muerte del Señor D. Manuel Galbán y Ventura», Manila, 1 de junio de 1769.

36. Sobre este particular ver LORENZO GARCÍA, Santiago, «La expulsión de los jesuitas filipinos: un ejemplo de disputa por el poder político», Revista de Historia Moderna (Anales de la Universidad de Alicante), núm. 15 (1996), pp. 179-200; o del mismo autor, La expulsión de los jesuitas de Filipinas, Universidad de Alicante, Alicante, 1999. 
ta de Nueva España, ya que sólo el San Carlos estaba listo para partir hacia Acapulco de forma inminente.

La arribada el 8 de julio del navío Buen Consejo al Puerto de Cavite parecía ofrecer a Raón y su equipo nuevas posiblidades ${ }^{37}$; el tiempo se encargó de hacer ver lo contrario ${ }^{38}$. Sin demora, se entablaron conversaciones con el capitán del buque Juan de Cassens, acordándose inicialmente que a sus órdenes marcharían 40 regulares hacia España. Esto fue ratificado en junta de gobierno de 22 de julio, donde se dispuso igualmente que 50 padres más fueran destinados al Santa Rosa y que «sólo se embarquen en dicha fragata San Carlos los restantes hasta el número liquidado; con que al mismo tiempo que el extrañamiento de todos se conseguirá el seguro del viaje, y comodidad deseada para dicha fragata San Carlos». El San Carlos navegaría por la vía de Nueva España hacia Cádiz, mientras que el Buen Consejo y la Santa Rosa lo harían bordeando el continente africano. El San José, que no fue terminado a tiempo, sería reservado para «las sucesivas ocurrencias de estas islas» ${ }^{39}$. Todos los cabos parecían ya bien atados, pero, como comprobaremos después, el extrañamiento por la ruta del Cabo de Buena Esperanza aún provocó algunos quebraderos de cabeza a la administración manileña.

Finalmente el San Carlos fue el único navío que efectuó la derrota de Nueva España con jesuitas filipinos a bordo. Gracias a la abundante documentación y al Diario del P. Francisco Javier Puig, conocemos con gran detalle su dilatado periplo. Sabemos, por ejemplo, que José Raón, temeroso ante otro posible fracaso, decidió reducir drásticamente el número de padres embarcados esta vez, en relación al primer viaje frustrado ${ }^{40}$.

El día 28 de julio el comisionado Basaraz ya tenía en sus manos un rol confeccionado por el Provincial Pazuengos con los nombres de los 21 regulares seleccionados para la expedición, entre los que haría las veces de Superior el P. Francisco Javier

37. El navío «Buen Consejo» fue construido en el año 1764 y posteriormente comprado a un particular por la Real Armada. Fue el primer buque español en navegar desde Cádiz a Filipinas por la vía del Cabo de Buena Esperanza, en 1765. Los mercaderes filipinos vieron en este acontecimiento un mal presagio para el fructífero comercio de Acapulco, vigente desde 1602; tanto fue así que cambiaron el nombre del navío por el de «Mal Consejo».

En el siglo XVIII, los navíos eran buques de guerra de gran envergadura, generalmente de más de 60 cañones -el Buen Consejo tenía 64-, con tres palos cruzados y bauprés.

En COSANO MOYANO, J., Una visión de Filipinas en el reinado de Carlos III, Real Academia de Ciencias, Bellas Letras y Nobles Artes de Córdoba, 1990, pp. 29-31; MOLINA, A., Historia de Filipinas, vol. I, Ediciones Cultura Hispánica del Instituto de Cooperación Iberoamericana, Madrid, 1984, p. 103; MANERA REGUEYRA, E. y otros, op. cit., pp. 402 y 417; y CUSHNER, N. P., Philippine Jesuits in Exile, Roma, 1964. p. 32.

38. A.H.N., Clero, Jesuitas, leg. 240: Consulta de José Raón al Conde de Aranda, Manila, 2 de agosto de 1769.

39. A.H.N., Clero, Jesuitas, leg. 241: Junta General de Real Hacienda, Manila, 22 de julio de 1769.

40. A.H.N., Clero, Jesuitas, leg. 240: Consulta de José Raón al Conde de Aranda, Manila, 2 de agosto de 1769. 
Puig, así como una «lista de la gente que se considera necesaria para el servicio y asistencia de los veinte y un jesuitas que se han de embarcar», formada por un mayordomo, un repostero, dos cocineros, un barbero y cinco sirvientes ${ }^{41}$. Al día siguiente se ordenó al factor de la Real Hacienda Juan Francisco Romay que se ocupase del «rancho para la manutención de dichos regulares, vestuario de su servicio, avio de sirvientes y demás que les sea preciso y permitido según concesión de S. M. en sus Instrucciones» ${ }^{42}$.

El día 3 de agosto a las diez de la mañana los jesuitas fueron conducidos a bordo de la nave, quedando al «cuidado y cargo del comandante de ella» ${ }^{43}$. A las cuatro de la mañana del día siguiente la fragata se hizo a la vela, llegando rápidamente al Estrecho de Mariveles, situado en la boca de la bahía de Manila. Exceptuando una pequeña tomenta al poco de salir y los típicos problemas de falta de agua y mal estado de algunos alimentos, según palabras de Cerain, se «consiguió una navegación de las más felices que se han hecho» ${ }^{44}$. Por fin, a media mañana del día de Navidad, el San Carlos echó anclas en el Puerto de Acapulco, como comunicaba en un despacho el virrey Marqués de Croix al Conde de Aranda ${ }^{45}$. Antes de desembarcar, se supo a bordo que la población se hallaba asolada por una devastadora epidemia, que tenía postrado en su lecho al mismo castellano de la plaza, Teodoro de Croix, sobrino del virrey. Por la tarde del día 26 los padres bajaron a tierra firme y fueron trasladados, por orden de las autoridades, a una fortaleza situada sobre un altozano ${ }^{46}$.

Por fin, el 20 de enero del año siguiente los 21 jesuitas retomaron el camino de su exilio rumbo a la ciudad de Veracruz, al otro lado del istmo mejicano, donde entraron el día 17 del mes siguiente ${ }^{47}$. Mientras duró su estancia allí los religiosos no pudieron salir del convento franciscano donde fueron confinados; sin embargo, el trato que les dispensaron, tanto los frailes franciscanos como las autoridades civiles de la localidad, fue siempre decoroso según Puig.

El día 1 de abril los expulsos partieron rumbo a la isla de Cuba a bordo de la urca San Julián ${ }^{48}$. La navegación hasta La Habana fue costosa por la falta de vientos y

41. A.H.N., Clero, Jesuitas, leg. 240: Diligencias de embarque de 21 jesuitas en el San Carlos, Manila, julio de 1769, y Consulta del comisionado Basaraz al gobernador José Raón, Manila, 30 de julio de 1769.

42. A.H.N, Clero, Jesuitas, leg. 240: El comisionado Basaraz al factor Juan Francisco Romay, Manila, 29 de julio de 1769.

43. A.H.N, Clero, Jesuitas, leg. 240: El comisionado Basaraz al gobernador José Raón, Puerto de Cavite, 3 de agosto de 1769 .

44. A.H.N., Clero, Jesuitas, leg. 240: Carta de Felipe Cerain al Marqués de Croix, virrey de Nueva España, bahía de Navidad, 12 de diciembre de 1769 .

45. A.H.N., Clero, Jesuitas, leg. 240: Consulta del Marqués de Croix, vierrey de Méjico, al Conde de Aranda, Méjico, 4 de enero de 1770.

46. Diario del P. Francisco Javier Puig, op. cit., pp. 108-110.

47. Ibidem, pp. 120-122.

48. A.G.S., Marina, leg. 724: Carta del Intendente de Marina de Cádiz Juan Gerbaut al Secretario de Marina e Indias Julián de Arriaga, Isla de León, 24 de agosto de 1770. 
corrientes marinas favorables. Así que la nave no fondeó en puerto hasta el 13 de mayo $^{49}$.

En Cuba, su gobernador y capitán general Antonio María Bucareli y Ursúa tenía ya por aquel entonces una dilatada experiencia en todo lo referente a las tareas de extrañamiento de los regulares. No en balde Cuba fue la avanzadilla en el exilio de la Compañía de Jesús en las Indias. Los escasos 21 padres que allí realizaban su labor misional abandonaron los dos colegios isleños de la Orden los días 15 y 16 de junio de 1767. Pero lo que hacía de La Habana un enclave crucial en la «operación cesárea» era su condición de encrucijada, como lugar de paso obligado de la flota de la Carrera de Indias. De modo que la capital cubana se convirtió en escala inexcusable y en depósito general de cientos de jesuitas que, procedentes de Indias y Filipinas, atravesaron el Atlántico rumbo a Europa entre 1767 y $1770^{51}$.

Otra vez fueron encerrados en un convento, esta vez de la orden betlemita, a la espera de ser embarcados nuevamente en la misma nave que les había traído desde Veracruz $^{51}$. El 4 de junio por la mañana la San Julián se hizo a la mar, acompañada por la flota de Nueva España, que en aquellos días había llegado también a La Habana desde Veracruz. Marchar en convoy ofrecía a priori la posibilidad de una travesía más segura hasta Cádiz. Pero estas esperanzas se esfumaron para los religiosos ese mismo día, al sufrir su buque una grave avería; al anochecer un ventarrón tronchó el mastelero mayor, que se hubo de cambiar apresuradamente. Pese a que la reparación fue rápida, la malograda nave quedó rezagada del resto de la escuadra, que no se detuvo por el percance de su compañera, llegando a España 18 días antes que ésta ${ }^{52}$. Junto a esta desgracia inicial, la «urca jesuita» hubo de hacer frente a los riesgos de una ruta marítima plagada de pasos peligrosos. Entre ellos, los inevitables cayos del Estrecho de Florida y los difíciles canales de las islas Bahamas, auténticas pesadillas incluso para los navegantes más avezados.

Los barcos que realizaban la derrota hacia el Viejo continente por el Atlántico estaban obligados a alcanzar los 38 ó 40 grados de latitud norte, con tal de beneficiarse de los famosos vientos del oeste, que soplan a popa de las embarcaciones que navegan en esta dirección. Finalmente hubo fortuna y, gracias a estos vientos, el 15 de julio ya se avistaron desde la San Juliân las dos islas más occidentales del archipiélago de las Azores: Flores y Corvo ${ }^{53}$. Pero no todo iba a ser tan sencillo y el 25 de julio,

La urca era una especie de fragata de carga, muy robusta, de mayor eslora de lo normal y muy ancha en su parte central. Fueron especialmente famosas en su época las urcas construidas en Holanda, muy eficaces en el transporte de mercancías.

En MANERA REGUEYRA, E. y otros, op. cit., p. 411.

49. Diario del P. Francisco Javier Puig, op. cit., p. 126.

50. MORENO ALONSO, Salud, «Bucareli y el paso de los jesuitas por Cuba camino del destierro», Actas del Congreso Internacional de Historia, Córdoba, 1993, p. 197.

51. Diario del P. Francisco Javier Puig, op. cit., p. 128.

52. Ibidem, p. 134.

53. Ibídem, p. 134. 
casi rozando las costas de Portugal, «se nos hechó encima un viento nordeste recio y tormentoso que nos agitó fuertemente por 6 días y sotaventó a los 34 grados de latitud septentrional con el recelo de que nos abatiesse sobre las costas del Reyno de Marruecos» ${ }^{54}$.

Por fin el 31 de julio, precisamente día de San Ignacio de Loyola, se hizo la calma, que ya siempre acompañó a la navegación hasta el Puerto de Santa María, donde la urca San Julián fondeó el 9 de agosto a las diez de la mañana, «vivos y sanos, aunque débiles y fatigados todos los 21 jesuitas que día I de agosto del año pasado 1769 salimos de Manila» ${ }^{55}$.

\section{NUEVOS PROBLEMAS LOGÍSTICOS POR LA RUTA DEL CABO DE BUENA ESPERANZA}

Como anticipamos, la expulsión del resto de padres filipinos por la ruta del Cabo de Buena Esperanza fue más problemática. .Creyendo ver en Juan de Cassens, capitán del Buen Consejo, una predisposición muy positiva, Raón confió en poder aumentar sin dificultad el número de religiosos que transportaría en su buque. De este modo sería posible prescindir de los servicios de la Santa Rosa, «con ahorro de los mayores gastos que debería ocasionar la referida expedición de la fragata» ${ }^{56}$.

Pero esta postura despertó los recelos del marino, quien en dos cartas enviadas al gobernador, con fechas de 19 de julio y 5 de agosto, negaba tajantemente esta posibilidad: «me será forzoso admitir los cuarenta religiosos, ni uno más». En las mismas, esgrimía una serie de argumentos que dejaron en fuera de juego al máximo responsable político de Manila. Explicaba Cassens que el Rey debía haberle informado, antes de su partida hacia el archipiélago, sobre el importante asunto que allí le esperaba, para prepararlo adecuadamente durante el trayecto de ida. Asimismo indicaba que la ruta que seguía el Buen Consejo, la del Cabo de Buena Esperanza, se veía amenazada desde hacía poco por el peligro inminente de guerra, de manera que era de mucha conveniencia «navegar los navios del Rey armados». Esta circunstancia hacía necesario ajustar al máximo el número de los pasajeros y la cantidad del rancho transportados. Además, afirmaba taxativamente que «del puerto no he de sacar ni un enfermo, especialmente de accidentes incurables, porque la navegación es muy dilatada y la variedad de climas cálidos y frígidos que he de encontrar trae consigo gravísimas enfermedades contagiosas y pestilentes ${ }^{57}$.

Las negativas de Cassens cayeron como un jarro de agua fría en Manila. Se optó por seguir negociando con el tozudo capitán, pero rescatando al mismo tiempo la so-

54. Ibidem, p. 136.

55. Ibidem, pp. 136-138.

56. A.H.N., Clero, Jesuitas, leg. 241: Carta del gobernador de Filipinas José Raón a Juan de Cassens, Manila, 3 de septiembre de 1769 .

57. A.H.N., Clero, Jesuitas, leg. 241: Cartas de Juan de Cassens al gobernađor José Raón, Santa Cruz, 19 de julio y 5 de agosto de 1769 . 
lución de la Santa Rosa de Lima. El 31 de agosto Raón dispuso que los pilotos José Valverde, Felipe Vieyra y Domingo Gutiérrez pasasen «a reconocer con toda prolijidad y esmero la fragata de $S$. M. nombrada Santa Rosa y sucesivamente expongan, a continuación, en presencia del Castellano de Cavite, que asistirá al cato del prevenido reconocimiento, qué número de regulares de la Compañía podrá conducir cómodamente al Puerto de Cádiz». Un día después el reconocimiento estuvo terminado. Los expertos «a una voz expusieron, que cómodamente puede llevar ochenta regulares de la Compañía».

Pese a todo, el 3 de septiembre el gobernador hizo un último intento por convencer a Cassens, comunicándole que lo más ajustado al Real Servicio era que los religiosos fueran despachados a Europa entre el Buen Consejo y una de las dos fragatas, la Venus o la Santa Rosa. Al día siguiente se produjo la contestación en un tono impertinente, advirtiendo que el asunto del traslado de los padres «es privativo a $V$. S., que verá cómo los manda». Cassens se permitió, además, el lujo de proponer nuevas soluciones de urgencia: utilizar el espacioso navío San José, junto con el de su mando, en el traslado de los jesuitas ${ }^{59}$.

Con ello la paciencia del gobierno de Manila se agotó definitivamente, decidiéndose finalmente prescindir de los servicios del Buen Consejo y utilizar otra fragata, la Venus, junto con la Santa Rosa, en las operaciones de expulsión ${ }^{60}$.

La Venus había fondeado en el Puerto de Cavite a mediados del mes de agosto. Sin dilación Raón también tanteó a su capitán González Guiral, preguntándole por carta cuántos jesuitas estaría dispuesto a transportar hasta Cádiz; la respuesta fue $22^{61}$. Si las negociaciones con Cassens fueron, como mínimo decepcionantes, las mantenidas con Guiral tuvieron un color muy distinto; en palabras de Raón, este «comandante se ha ofrecido con muy distinta disposición» ${ }^{62}$.

A finales de diciembre esa buena predisposición le llevó incluso a proponer a Basaraz el aumento del número de padres que podría transportar en su navío, sobre lo acordado inicialmente:

«...llevaré veintidós regulares de la Compañía en la fragata de mi mando, los que irán medianamente acomodados como verá Vuesamerced, pero si precisa mucho el que lleve algunos más, puede Vuesamerced servirse poner hasta veinticuatro, en inteligencia que quedarán más estrechos» ${ }^{63}$.

58. A.H.N., Clero, Jesuitas, leg. 241: Reconocimiento de la fragata Santa Rosa por los marinos José Valverde, Felipe Vieyra y Domingo Gutiérrez, Puerto de Cavite, 1 de septiembre de 1769.

59. A.H.N., Clero, Jesuitas, leg. 241: Carta de Juan de Cassens al gobernador José Raón, Santa Cruz, 4 de septiembre de 1769.

60. A.H.N., Clero, Jesuitas, leg. 241: Junta General de Real Hacienda, Manila, 9 de octubre de 1769.

61. A.H.N., Clero, Jesuitas, leg. 241: Carta del gobernador José Raón a Manuel González Guiral, capitán de la Venus, Manila, 23 de agosto de 1769, y Carta de González Guiral al comisionado Basaraz, Santa Cruz, 24 de diciembre de 1769.

62. A.H.N., Clero, Jesuitas, leg. 241: Consulta del gobernador de Filipinas José Raón al Rey, Manila, 11 de enero de 1770 .

63. A.H.N., Clero, Jesuitas, leg. 241: Carta de González Guiral al comisionado Basaraz, Santa Cruz, 24 de diciembre de 1769. 
De este modo, al comenzar el año 1770 , ya se había decidido qué buques llevarían a los jesuitas hasta España por la ruta del Cabo de Buena Esperanza, y cuántos sujetos viajarían en cada uno de ellos ${ }^{64}$ : las fragatas de Su Majestad la Venus, con 24 padres a bordo, y la Santa Rosa de Lima, con 68, serían las encargadas ${ }^{65}$.

Para la Santa Rosa el gobernador hubo de aprestar con toda celeridad una tripulación de emergencia, formada por marinos que servían a la Corona en la provincia filipina, entre ellos el que fue nombrado su capitán, el oficial de la Marina Real José de Soroa, destinado en el archipiélago desde $1757^{66}$.

El siguiente aspecto importante que se trató fue el de las provisiones. En los primeros días de enero de 1770 también se resolvió el asunto del rancho de la fragata Venus. El día 5 González Guiral certificó haber recibido de la Caja de Temporalidades 7.000 pesos para este fin ${ }^{67}$. Un mes antes, cuando aún se creía que serían 22 los regulares embarcados, el marino ya había dado al gobierno de Manila muestras de buena voluntad también en esta cuestión:

«Si las Cajas no tuviesen caudal para suplir los gastos de rancho que ocasionasen los veintidós regulares, estoy igualmente pronto a llevarlos sin los auxilios expresados, buscándolos yo para el efecto" ${ }^{6 .}$.

El día 19 de enero de 1770 , sobre las cuatro de la tarde, el comisionado Basaraz se presentó en el muelle de Cavite en compañía del escribano público Martín Domínguez Zamudio, de los 24 regulares designados para embarcar en la Venus y de 4 criados que deberían atenderlos durante la travesía ${ }^{69}$. A bordo les esperaba González Guiral, quien informó de los preparativos efectuados en su nave para acomodar a los padres: el «alojamiento lo tenían dispuesto bajo el alcázar a la banda de babor, en catres levadizos, donde podrían navegar con conveniencia» ${ }^{70}$. Al día siguiente de ma-

64. A.H.N., Clero, Jesuitas, leg. 241: Consulta del gobernador de Filipinas José Raón al Rey, Manila, 11 de enero de 1770.

65. La Venus era una fragata de 28 cañones, construida en el año 1756 en la atarazana de La Carraca (Cádiz). La Venus ya había sido utilizada con anterioridad en el traslado de jesuitas desde las provincias americanas hasta el Puerto de Santa María.

En A.G.S., Marina, leg. 724; y HANISCH ESPINDOLA, Walter, Itinerario y pensamiento de los jesuitas expulsos de Chile, 1767-1815, Editorial Andrés Bello, Santiago de Chile, 1972, p. 39.

Por su parte, la fragata Santa Rosa de Lima tenía 22 cañones, fue construida en 1742 y adquirida por la Armada Real en el extranjero.

En MANERA REGUEYRA, E. y otros, op. cit., pp. 419 y 420.

66. A.H.N., Clero, Jesuitas, leg. 241: Consulta del gobernador José Raón al Rey, Manila, 11 de enero de 1770; y A.H.N., Clero, Jesuitas, leg. 278: Carta de José de Soroa al Conde de Aranda, bahía de Cádiz, 10 de agosto de 1770 .

67. A.H.N., Clero, Jesuitas, leg. 241: Certificación de Manuel González Guiral, Santa Cruz, 5 de enero de 1770.

68. A.H.N., Clero, Jesuitas, leg. 241: Carta de González Guiral al gobernador José Raón, Santa Cruz, 9 diciembre de 1769.

69. A.H.N., Clero, Jesuitas, leg. 242: Diligencias de Basaraz y del escribano real y público Martín Domínguez Zamudio, a bordo de la fragata Venus, Puerto de Cavite, 19 de enero de 1770.

70. Ibidem. 
drugada la Venus zarpó, comenzando la derrota del Cabo de Buena Esperanza hacia el Puerto de Santa María ${ }^{71}$.

Tener a punto las provisiones para los 68 jesuitas de la Santa Rosa resultó evidentemente más complicado. Además de los víveres, el capitán Soroa solicitó al comisionado Basaraz «cinco o seis mil pesos», destinados a afrontar las hipotéticas contingencias de la travesía ${ }^{72}$. Este imprevisto impidió que las dos fragatas partiesen juntas. Para el día 22 el gobierno ya había conseguido el dinero demandado por Soroa. Por la tarde Basaraz subió a bordo, acompañado por los regulares y 12 criados, y entregó 6.000 pesos al contador de la embarcación Manuel Antonio Aguirre ${ }^{73}$. Junto al navío Buen Consejo, que partió sin jesuitas entre su pasaje, la Santa Rosa se hizo a la mar el 23 de enero, siguiendo la estela de la Venus ${ }^{74}$.

Según nos cuenta el P. Puig, en líneas generales la travesía transcurrió «con buenos tiempos». Pese a salir en fechas distintas, las fragatas se encontraron a la altura de las islas de Java y Sumatra, navegando a partir de este momento en convoy y «con bastante felicidad hasta ponerse muy cerca de El Cabo de Buena Esperanza, en cuio meridiano se hallaron a principios de abril ${ }^{75}$. Fue en ese momento cuando las tripulaciones tropezaron con los únicos peligros reseñables, en forma de fuertes ventiscas, que retrasaron la marcha y obligaron a efectuar escala en la isla de San Mauricio, separándose las naves nuevamente. Por fin se consiguió remontar los días 3 y 4 de mayo el Cabo de Buena Esperanza, para recalar más tarde en la isla de Santa Elena en busca del aprovisionamiento de la necesaria aguada ${ }^{76}$.

La Venus y la Santa Rosa partieron de la isla a finales de mayo, decidiendo los capitanes de las dos fragatas continuar la derrota hacia Cádiz otra vez unidos. Por lo visto, la sobrecargada Santa Rosa maniobraba con dificultad y, según palabras del patrón de la Venus, su «poco andar ha dilatado mi viaje más de quince días»"

71. A.H.N., Clero, Jesuitas, leg. 278: Nómina de los 24 jesuitas embarcados en la fragata Venus, Carta de Manuel González Guiral al comisionado Basaraz, Puerto de Cavite, 19 de enero de 1770.

72. A.H.N., Clero, Jesuitas, leg. 241: Carta de José de Soroa al comisionado Basaraz, Manila, 18 de enero de 1770 .

73. A.H.N., Clero, Jesuitas, leg. 241: Diligencias del comisionado Basaraz a bordo de la Santa Rosa, Puerto de Cavite, 22 de enero de 1770.

74. A.H.N., Clero, Jesuitas, leg. 278: Nómina de los 68 jesuitas embarcados en el Santa Rosa de Lima, Carta de su capitán José de Soroa al Conde de Aranda, bahía de Cádiz, 10 de agosto de 1770.

75. Diario del P. Francisco Javier Puig, op. cit., pp. 140-142.

76. A.H.N., Clero, Jesuitas, leg. 242: Carta de González Guiral al Conde de Aranda, bahía de Cádiz, 10 de agosto de 1770.

Al igual que ciertos alimentos, el agua también se corrompía con mucha frecuencia. Por eso resultaban imprescindibles estas escalas en las navegaciones de largo recorrido.

Ver LÓPEZ-RÍOS FERNÁNDEZ, Fernando, Historia médica de las navegaciones colombinas (1492-1504), Acta Histórico-Médica Vallisoletana XLI, Secretariado de Publicaciones Universidad de Valladolid, Valladolid, 1993, p. 46.

77. A.H.N., Clero, Jesuitas, leg. 242: Carta de González Guiral al Conde de Aranda, bahía de Cádiz, 10 de agosto de 1770 . 
A estos problemas se añadieron, a estas alturas, los efectos del cansancio y del escorbuto, que comenzaron a dejar su huella en los misioneros más débiles ${ }^{78}$. En el último tercio del viaje fallecieron siete padres por estos motivos, tres en la Santa Rosa y cuatro más a bordo de la Venus ${ }^{79}$.

Finalmente los ochenta y cinco restantes entraron en la bahía de Cádiz sin más problemas el 10 de agosto, tan sólo un día después que lo hizo el San Carlos Borromeo:

«Raríssima fue esta contingencia y digna de la admiración de muchos que la reflexionaron, que aviendo sido dividida nuestra pequeña provincia con tal separación y despachada de Manila para el destierro con diferencia de casi medio año los unos de los otros, y por vías tan opuestas como es los unos seguir el curso del sol de oriente a poniente, y los otros por el contrario de poniente a oriente, dando entre unos y otros perfecto giro al orbe terráqueo al acabar de unir la esfera, llegamos casi juntos a un mismo tiempo a Cádiz con sola la diferencia de 24 horas» ${ }^{80}$.

\section{DE CÁDIZ HACIA EL DESTIERRO ITALIANO: LOS REGULARES FILIPINOS EN LA SPEZIA}

En el Puerto de Santa María, los encargados de las labores de envío a Italia de los jesuitas procedentes de ultramar fueron el Conde de Trigona, gobernador de la plaza desde 1765, el comisionado militar Marqués de la Cañada, y Juan Gerbaut, Intendente de Marina de Cádiz. Mientras los dos primeros se ocuparon de «la manutención, de habilitarlos de cuanto necesiten para su aseo y comodidad en el viaje», Gerbaut tuvo como misión procurar las embarcaciones y las provisiones necesarias para el transporte de los padres ${ }^{81}$. Sin embargo, la escasez de dinero disponible para estos menesteres era ya un mal crónico, y la inesperada arribada del convoy de Filipinas trastocó aún más el ritmo normal de trabajo en el Puerto de Santa María, pues «esta novedad hizo variar las disposiciones, en lo que precisaba aumentar el número de buques» ${ }^{82}$. Los esfuerzos de Gerbaut consiguieron tener a punto la urca sueca Gran Vicente para principios de septiembre de 1770 , pero a última hora se decidió que entre los 130 regulares embarcados, «americanos de distintas provincias», no fuesen filipinos $^{8.3}$. Éstos hubieron de esperar.

78. Diario del P. Francisco Javier Puig, op. cit., p. 140.

79. A.H.N., Clero, Jesuitas, leg. 278: Relación de los jesuitas transportados en la fragata Santa Rosa de Limar, José de Soroa, Puerto de Santa María, 10 de agosto de 1770; y A.G.S., Marina, leg. 724: Manuel González Guiral, comandante de la fragata Venus, al Secretario de Marina e Indias Julián de Arriaga, Puerto de Santa María, 10 de agosto de 1770.

80. Diario del P. Francisco Javier Puig, op. cit., p. 138.

81. A.G.S., Marina, leg. 724: Carta del Intendente Juan Gerbaut al Secretario de Marina e Indias Julián de Arriaga, Isla de León, 24 de agosto de 1770.

82. A.G.S., Marina, leg. 724: Carta del Intendente Juan Gerbaut a Julián de Arriaga, Isla de León, 24 de agosto de 1770; y Carta del Marqués de la Cañada a Gerbaut, Puerto de Santa María, 30 de julio de 1770.

83. A.G.S., Marina, leg. 724: El Intendente Juan Gerbaut a Julián de Arriaga, Isla de León, 7 de septiembre de 1770 . 
Por lo visto, la permanencia en el puerto gaditano no fue muy grata a los hijos de San Ignacio. De acuerdo con la versión del P. Puig, a las incómodas condiciones de alojamiento, las autoridades añadieron continuos y farragosos interrogatorios, que consiguieron agotar a los padres más pacientes ${ }^{84}$. Al fin el 14 de octubre los jesuitas filipinos, junto con otros americanos, en total más de 140 , subieron a bordo del recio navío sueco La Navegación, que se hizo a la vela cuatro días después al atardecer ${ }^{85}$. El viaje fue tranquilo y en seguida se arribó a destino:

"Dios Nuestro Señor teniendo misericordia de nosotros más que los hombres nos providenció de buenos vientos y con esto se nos abreviaron los trabajos de esta navegación. Pues día 29 del mismo mes por la tarde dimos fondo en Puerto Especie» ${ }^{* 6}$.

Los padres de ese nuevo contingente comenzaron entonces a distribuirse territorialmente según lo ordenado desde Madrid ${ }^{87}$. Los jesuitas filipinos debieron encaminarse a Bagnacavallo y Lugo, cerca de Rávena, poblaciones que les habían sido asignadas $^{88}$.

\section{EL NUEVO GOBERNADOR SIMÓN DE ANDA EXPULSA A LOS ÚLTIMOS JESUITAS DE FILIPINAS}

Mientras, lejos, en las Filipinas, todavía quedaban algunos miembros de la Compañía de Jesús. Fue en tiempos del gobernador Simón de Anda y Salazar (1770-1776) cuando se dieron por terminadas las operaciones de extrañamiento. Anda ya conocía la realidad del archipiélago, pues había desempeñado el cargo de oidor en la Real Au-

84. Diario del P. Francisco Javier Puig, op. cit., pp. 142-144.

85. HANISCH, Walter, Itinerario y pensamiento de los jestitas expulsos de Chile (176-1815), Ed. Andrés Bello, Santiago de Chile, 1972, p. 81; y Diario del P. Francisco Javier Puig, op. cit., p. 144.

Fueron muchos los barcos extranjeros fletados por los Intendentes de Marina en la Península: sue$\cos$, holandeses, ingleses, daneses, franceses, etc. Pocos días antes de la partida hacia Italia del navío sueco La Navegación, habían zarpado del Puerto de Santa María el navío inglés El Terror el 21 de agosto de 1770 , con 19 jesuitas a bordo, y, como ya apuntamos, la urca sueca Gran Vicente el 5 de septiembre, transportando otros 130 regulares americanos.

En GIMÉNEZ LÓPEZ, E., op. cit; y A.G.S., Gracia y Justicia, leg. 724: El Intendente Juan Gerbaut a Julián de Arriaga, Isla de León, 21 de agosto y 7 de septiembre de 1770 .

86. Diario del P. Francisco Javier Puig, op. cit., p. 144.

87. Los padres de las provincias de Castilla y parte de los de Méjico fueron a parar a Bolonia; los de Aram gón, Perú y los restantes de Méjico a Ferrara; los de Chile a Ímola, Rávena y Cesena; los de Paraguay a Faenza y Rávena; los de Toledo a Forli y Rávena; los andaluces a Rímini y Rávena; los de Santa Fe y Quito a Ancona, Urbino, Rávena y Faenza; y por último los de Filipinas a Bagnacavallo, Lugo y Ferrara.

En GIMÉNEZ LÓPEZ, Enrique y MARTÍNEZ GOMIS, Mario, «La Secularización de los Jesuitas expulsos», Hispania Sacra, núm. 47 (1995), p. 470; y CUSHNER, N. P., op. cit., p. 35.

88. Las dos localidades se encuentran al nordeste de Italia en la actual región administrativa de Emilia-Romagna, dentro de la provincia de Rávena, y cerca de la ciudad de Bolonia. Bagnacavallo, antigua Tiberiacum, es hoy en día una población muy pequeña, mientras que Lugo (lá vieja Lucus), por su mayor entidad demográfica y económica, alcanza el rango de pequeña ciudad. 
diencia de Manila desde 1761 hasta $1765^{89}$. Alcanzó fama y reconocimiento, al resistirse con tenacidad y valor a la ocupación inglesa de las Islas entre 1762 y 1764 . Fue precisamente en esta época cuando surgieron ciertas desavenencias, cuando no abiertos enfrentamientos, con algunos miembros de la Compañía de Jesús, a los que acusó de connivencia con el enemigo invasor.

El 12 de febrero de 1767 don Simón marchó a la Península a bordo del Buen Consejo para ocupar el cargo de consejero de Castilla, pero en julio de 1770 retornó al archipiélago en calidad de gobernador y capitán general ${ }^{\circ}$, según el P. Luengo «para echar de allí a los jesuitas, que fue el fin de haberle enviado alla [...], para que sigan el mismo camino algunos pocos que quedaban allá por enfermos, a poco que se hayan reparado y tomado fuerzas» ${ }^{91}$. Es claro que, en esas fechas, era público y notorio el antijesuitismo del enérgico ministro, y que Luengo y el resto de sus compañeros de orden lo conocían.

En septiembre de 1770 Anda procesó a su antecesor en el cargo y a algunos ministros de la Audiencia como Basaraz, acusándoles de haber actuado con negligencia en el negocio de los jesuitas, y el 20 de noviembre ordenó que un equipo de médicos reconociera a los veinte regulares de la Sociedad ignaciana que aún quedaban en los conventos de Santo Domingo, San Francisco, San Agustín y San Juan de Dios, en Manila, con vistas a su posible traslado a Europa. Los doctores Eduardo Wogan, Antonio Martínez y Agustín Eusebio Fabre efectuaron los exámenes en los primeros días de diciembre. El dictamen de los especialistas fue el siguiente:

"Todos ellos adolecen de enfermedades graves y habituales, pero que, sin embargo de esto, a los dichos Padres Juan Manuel Alonso, Francisco Ortiz Zugasti, Manuel Zuazua, Domingo Insausti, Joaquín Ramos, Antonio Raucher, Rafael Rivera y Alejandro Mayneri los consideran capaces de emprender viaje a España por el Cabo de Buena Esperanza, aunque con algún trabajo y peligro. Y también hallan que de los cuatro dementes que se numeran entre los restantes, que son los dichos Miguel Quesada, Juan Fernández, Andrés Rodríguez y José Ambrosio, los tres últimos podrán emprender el mismo viaje con tal que se destine persona o personas que los cuide y tenga siempre a la vista, para evitar cualquier inconveniente que pueda excusar la demencia, por ser estos dementes melancólicos y no padecer accidentes corporales; y no el dicho Miguel Quesada, por ser lo furioso que causaría gravísima incomodidad a toda la tripulación, y que todos los demás se hallan por ahora incapaces absolutamente de emprender dicho viaje por la suma gravedad de sus accidentes $»^{92}$.

89. Su nombramiento como oidor supernumerario de la Audiencia de Manila tiene fecha de 18 de octubre de 1755, aunque Anda no pudo tomar posesión de ese cargo hasta el 21 de julio de 1761.

En RODRÍGUEZ RODRÍGUEZ, Isacio, «Simón de Anda y Salazar, precursor de la Sociedad de Amigos del País de Filipinas», en La Real Sociedad Bascongada y América (1992), p. 475.

90. CUSHNER, N. P., op. cit., p. 23.

91. A.H.L., Est. 10, PIs. 4, 5 y 6: LUENGO, Manuel, Diario de la expulsión de los jesuitas (1767-1814), Tomo V, 1771, p. 242.

92. A.H.N., Clero, Jesuitas, leg. 245: «Testimonio de las diligencias del reconocimiento de los veinte regulares de la Conpañía que por enfermos, viejos y dementes han quedado en estas Islas y se hallan depositados en los conventos de Santo Domingo, San Francisco, San Agustín y San Juan de Dios de 
Hacia mediados de diciembre el gobernador decidió que fueran nueve los padres expulsados a principios del año siguiente, por la ruta del Cabo de Buena Esperanza. La fragata Astrea -el mismo navío en el que había llegado algunos meses antes Anda- fue elegida para tal fin ${ }^{93}$. Así fue comunicado al capitán del buque José de Córdoba el 17 de diciembre ${ }^{94}$. En los últimos días de diciembre Córdoba recibió de manos de los oficiales de la Real Hacienda 3.267 pesos, procedentes de la Caja de Temporalidades, para hacer frente a los gastos ocasionados por los jesuitas durante la tra-

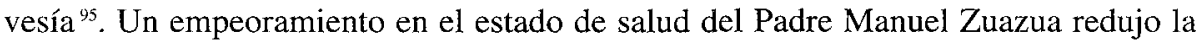
nómina definitiva del grupo del Astrea a 8 expulsos ${ }^{96}$, los cuales, encabezados por el oidor Juan Antonio de Uruñuela, fueron embarcados el 4 de enero de 1771, partiendo ese mismo día hacia el Puerto de Santa María ${ }^{97}$.

Durante el viaje del Astrea falleció el P. Domingo Insausti, de manera que tan sólo siete jesuitas arribaron el 2 de agosto de 1771 al Puerto de Santa María, siendo recibidos por el gobernador de la plaza Conde de Trigona y por el comisionado Marqués de la Cañada. Este último se trasladó al día siguiente al almacén, donde habían sido guardados el rancho sobrante y el equipaje de los siete regulares, y realizó el inventario de todos los efectos ${ }^{98}$.

Ignoramos el nombre de la nave y la fecha de su embarque en el Puerto de Santa María, pero sí sabemos que, meses más tarde, esos padres se reunieron con sus compañeros de provincia en la Península Itálica. Por ahora, las escasas noticias que tenemos nos las ofrece el Diario del P. Luengo, que nos informa de que los regulares del Astrea pasaron el invierno de 1772 en Génova, donde fueron acogidos con muy pocas atenciones por los religiosos residentes en su casa profesa, dirigida por el P. Durazo. Según el testimonio del diarista, fue norma el que los jesuitas españoles no encontraran, entre sus homólogos italianos, el calor que hubiesen deseado recibir en circunstancias tan adversas. A principios de mayo los últimos jesuitas filipinos, de camino hacia Bagnacavallo y Lugo, se encontraron en Bolonia con sus hermanos de Castilla y Nueva España ${ }^{9 y}$.

esta ciudad, practicado a fin de saber quienes de ellos se hallan capaces de emprender viaje a España en la presente ocasión, e información de testigos sobre la libertad con que han andado y hablado en dichos conventos», Manila, noviembre-diciembre de 1770.

93. La Astrea era una fragata de 34 cañones, construida en el año 1756 en los astilleros de Cartagena.

En MANERA REGUEYRA, E. y otros, op. cit., p. 420.

94. A.H.N., Clero, Jesuitas, leg. 245: Carta del gobernador de Filipinas Simón de Anda al capitán de la fragata Astrea José de Córdoba, Manila, 17 de diciembre de 1770.

95. A.H.N., Clero, Jesuitas, leg. 245: El capitán del Astrea José de Córdoba, Manila, diciembre de 1770.

96. A.H.N., Clero, Jesuitas, leg. 243: «Diligencias de fe de muerte del P. Manuel de Zuazua», Manila, 1771.

97. A.H.N., Clero, Jesuitas, leg. 245: Relación de jesuitas embarcados en la fragata Astrea, su capitán José de Córdoba, Puerto de Cavite, 4 de enero de 1771.

98. A.H.N., Clero, Jesuitas, leg. 827: «Inventario de parte del rancho hecho para la manutención de religiosos venidos de islas Filipinas en la fragata de S. M. nombrada la Astrea», Marqués de la Cañada, Puerto de Santa María, 3 de agosto de 1771.

99. A.H.L., Est. 10, Pls. 4, 5 y 6: LUENGO, Manuel, Diario de la expulsión de los jesuitas (I767-I814), Tomo VI, 1772, pp. 114-115. 
A finales del año 1772 el nuevo comisionado para el negocio de los jesuitas Juan Francisco Anda ${ }^{109}$ tuvo noticia de la inminente arribada de la fragata Venus a Filipinas. De acuerdo con el gobernador, decidió que tres doctores examinasen, por enésima vez, a los siete jesuitas que aún permanecían en Manila para determinar si podrían viajar hacia el destierro. Antonio Martínez, médico del Real Hospital de esa plaza, Francisco Fernández, primer cirujano de la Venus, y Diego Rendón, cirujano de la Real Armada, efectuaron los exámenes. Seis de los padres residían en el Hospital de Convalecencia de San Juan de Dios y el otro en el Convento de Santo Domingo.

Los facultativos resolvieron finalmente que «eran de parecer que ninguno de los referidos siete padres se podia embarcar para hacer un viaje tan largo, pues hay experiencia de que los dos primeros, habiéndolo emprendido en la fragata San Carlos $y$ vuelto de arribada, llegaron in articulo mortis; a más de que las enfermedades de que adolecen todos, las tienen por cuasi incurables, aun estando en tierras donde los alimentos, las medicinas y el descanso y otras comodidades están en mejor proporción que a bordo» ${ }^{101}$.

Esos pocos religiosos fallecieron en los años sucesivos en distintos hospitales de la capital manileña, casi todos ellos «dementes», según el diagnóstico de los galenos ${ }^{102}$. Es llamativo que la «locura» marque las vidas de los últimos jesuitas que quedaron en las Islas; fenómeno que se dio también frecuentemente en el resto de las provincias hispanas. Intuimos que el desconcierto y la incomprensión, a veces en forma de profundos estados depresivos, que estos padres debieron experimentar ante la quiebra total del Instituto ignaciano, al que habían dedicado gran parte de su vida y su trabajo, fueron interpretados por las autoridades, e incluso por los médicos, como «insensatez».

A modo de conclusión podemos decir que, debido a la insularidad y la lejanía, la Marina fue el instrumento fundamental dentro de la operación de expulsión en Filipinas. En aquella provincia la expatriación de la Sociedad de Jesús se vio dificultada por una serie de problemas logísticos. Pertrechar los navíos que debían transportar a los padres hacia Europa fue el principal inconveniente para las autoridades isleñas. La lógica demora motivada por la vuelta del San Carlos, dañado por una tormenta, y unos pocos errores administrativos en la confección de las listas de embarque preocuparon también en Manila y en Madrid.

100. Juan Francisco Anda era sobrino de Simón de Anda, y desde 1769 desempeñaba el cargo de oidor de la Real Audiencia de Manila. Sucedió a Domingo Blas de Basaraz como juez comisionado para el extrañamiento de los jesuitas en el año 1772.

En BURKHOLDER, Mark A. y CHANDLER, D. S., De la impotencia a la autoridad. La Corona española y las audiencias en América (1687-1808), F.C.E., Méjico, 1984, pp. 272-273; y SCHÜTTE, J. F., op. cit, p. 131.

101. A.H.N., Clero, Jesuitas, leg. 244: Consulta del comisionado Juan Francisco Anda al Rey, Manila, 30 de diciembre de 1772 .

102. A.H.N., Clero, Jesuitas, leg. 243: Consulta del gobernador de Filipinas José Basco y Vargas al Rey, Manila, 14 de junio de 1785 . 
Pese a todo, podemos afirmar que, en las Islas, la salida de los jesuitas se desarrolló por cauces normales bajo el gobierno de Raón. Y el mejor refrendo para esta aserción lo hallamos en la sentencia pronunciada por el Consejo Extraordinario algunos años más tarde. En ella se declaraba al antiguo gobernador inocente de la acusación de haber ejecutado con negligencia y dolo su comisión para el negocio de los jesuitas, y se disponía asimismo que su honor fuese limpiado de forma inmediata, pues el extrañamiento de Filipinas «se verificó enteramente con la mayor tranquilidad» ${ }^{103}$.

103. A.G.S., Gracia y Justicia, leg. 691: Consulta del Consejo Extraordinario, 7 de junio de 1776. 